\title{
SMART STREET LIGHTING SYSTEM BASED ON IOT TECHNOLOGY AND PIEZOELECTRIC SENSORS
}

\author{
Marwan Mustafa, ${ }^{1, *}$, Mohammad M. Ismail $^{2}$ \\ ${ }^{1}$ Mechanical Engineering Department, Faculty of Engineering, Al-Azhar University, Cairo, Egypt. \\ ${ }^{2}$ Mechanical Engineering Department, Faculty of Engineering, Al-Azhar University, Cairo, Egypt. \\ *Corresponding Author Email: eng.maro.2000@gmail.com \\ Received: 27 July 2021 Accepted: 10 August 2021
}

\begin{abstract}
This paper concentrates on the necessity of having a smart street lighting system, which is applicable in several roadways to provide conservation of energy. The method of the invoked implementation and the embedded smart system tools guarantee the necessity of the automation process from a primitive illumination operation to a quite intelligent illumination system. To solve intractable issues possibly taking place in primitive illumination operations related to roadways energy harvesting, the priority is considered for the presence of autonomous microelectronic systems having a great inevitability to make conservation of energy in order not to squander. The present prototype utilizes a piezoelectric sensor to detect the traffic situation of vehicles. The system employs a light-dependent resistor (LDR) to differentiate between daylights and evening times. This makes the smart street lighting system based on the internet of things (IoT) and gathers these processes, transmits, and receives information with no human interaction. This affords the capability of continuity of conservation of energy, diminishes the cost of manpower, and decreases the maintenance expenses, where the selection of LED street lamps is effectively to be instead of yellow sodium bulbs or white metal halide lamps, which are more costly and have bad environmental impacts.
\end{abstract}

KEYWORDS: Smart lighting system, Energy conservation, Energy harvesting, Piezoelectric sensor, Light-dependent resistor, Internet of things.

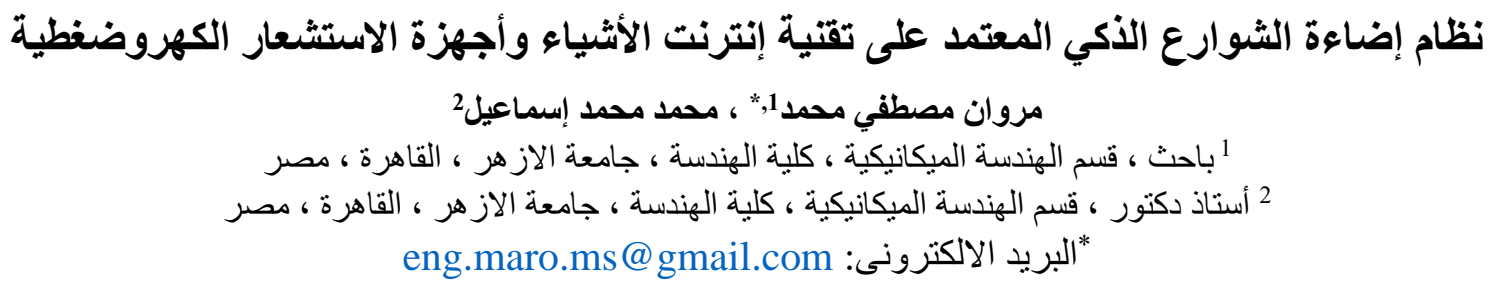




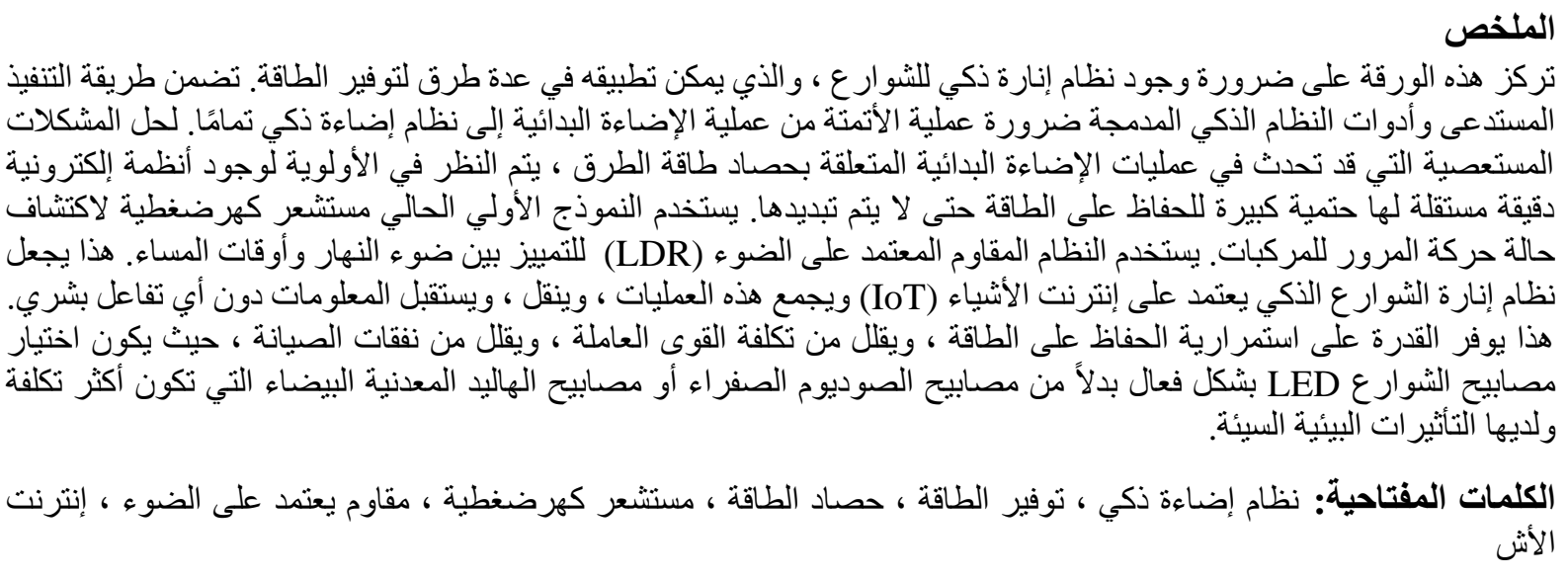

\section{INTRODUCTION}

It is noticeable that, in the last few years, energy harvesting for the goal of supporting low-power electronic sensor systems has received great attention. Hence, electricity has played one of the most important principal role, where conservation of energy and converting squandered energy into electrical power is becoming necessary nowadays [1].

For that, this project presents an automated solution to manage the process of illumination of the street bulbs in an effective way, considering the movement of vehicles in daylight and in the evening. Thus, our followed automated solution was including the utilization of an autonomous microelectronic system that featured by low power consumption to be applied in a smart street lighting system, which can present a great success in the conservation of energy [2,3].

Hence, the proposed smart street lighting system is composed of a combination of several techniques. One of the utilized techniques were piezoelectric sensors that embedded in roadways to detect vehicles movement. Another detector was required as a light-dependent resistor (LDR) which is responsible for checking whether if the time is daylight morning or dark night. In addition, the employment of wireless sensor network (WSN) technology instead of utilizing wired communication has been required; where, the wireless sensor network technology represented by using the internet of things (IoT) protocol for wireless data transmission [9]. Additionally, the usage of a clean source of energy as a solar panel to support the project with the required power was required [5], and finally, storing the surplus conducted energy in a rechargeable battery to support the whole system at night with the electric power required. Therefore, this automated solution of the smart street lighting system assured reducing the workforce, which is currently a hotly debated matter, so that regulating streetlights during daytime and night, without human involvement.

\section{PROBLEM DEFINATION}

Nowadays, electricity is a fundamental demand for human life and for the development of all economic sectors. Often at this time, the production of electricity has achieved by entirely different varieties of techniques. However, the main purpose of this project is to produce electricity by a non-conventional approach through a piezoelectric sensor and a clean renewable source of energy (solar panel). Nevertheless, what presented an intractable problem in recent days was the shortage of electricity in several sectors [10].

In context to solve this problem, there is no solution, but to reduce the power consumption as doing in the conservation of squandered energy in the streetlights.

Hence, this paper will concentrate on reducing the problem of power loss in streets, where due to the passage of vehicles on roadways, a considerable amount of potential energy had dissipated due to superficial friction. 
In addition, other limitations which could not be forgotten as the wiring technique, where a large cost of the installation and communicating the devices of the system with each other with this technique has been considered uneconomically; besides, the system reliability would be diminished too.

In spite, this system will resolve great issues of streetlamps, but in past existing technologies the managing of streetlights have been performed by manual action, thus the system would include human interaction that may cause several errors. while another prominent problem was often have been seen in streetlights, where even in daylight some lights bulbs were turned on, while sometimes streetlights were turned off even when the night has settled in; therefore, executing the automation of system for the streetlights cannot allow a huge amount of energy to be dissipated. Finally, the usage of LED bulbs instead of others will enable solving a grand environmental problem; where in the past used street light bulbs would have great passive impacts as were happened by yellow vapour sodium lamps or white metal halide lamps, where rarely people were taking the initiative to report for bad streetlamps in their locality [4].

\section{OBJECTIVES}

The direct piezoelectric effect stress that applied on the piezoelectric sensor due to the passage of vehicles will create a superficial vibration stress at the evening time $[6,11]$. Hence, the piezoelectric sensor will produce an output analog signal that will be converted to a digital signal, then transmitted to the main microcontroller unit, which was the IoT card, where the IoT transmitter card will process and identify the coming information which relevant to the state of the traffic situation. In consequence of the received data from the piezoelectric sensor and light-dependent resistor (LDR-1) to the IoT transmitter card [5], a wireless signal protocol will communicate between the IoT transmitter and transceiver card. Where the transceiver IoT card will have the capability to give a right decision regarding illumination of streetlights whether it will be a Z-shaped lighting system or a full capacity illumination system. Hence, the main aim of conservation of energy achieved through an intelligent embedded street light system without human intervention, in addition to a significantly improving of the efficiency of the harvested energy.

\section{METHODOLOGY}

Here, in Fig. 1 the block diagram discloses the basic working principle of the proposed system to convert the kinetic vibrational energy into electric power. Hence, the piezoelectric transducers deployed on the roads, where the analog output signal of the piezoelectric transducer will be digitalized by the Analog-Digital Converter; then transmitted to the IoT transmitter controller unit, which determines the state of motion of vehicles and pedestrians $[8]$.

However, the energy obtained from the solar panel is stored in a rechargeable Lithium-ion battery, where it utilized as a power supply for the whole circuit of the system in the darkness. Subsequently, the IoT transceiver controller unit receives a wireless sub-1 GHz signal from the IoT transmitter controller unit, thus the IoT transceiver controller affords a decision to the relay to switch between the z-shaped lighting system and full capacity illumination [10]. 


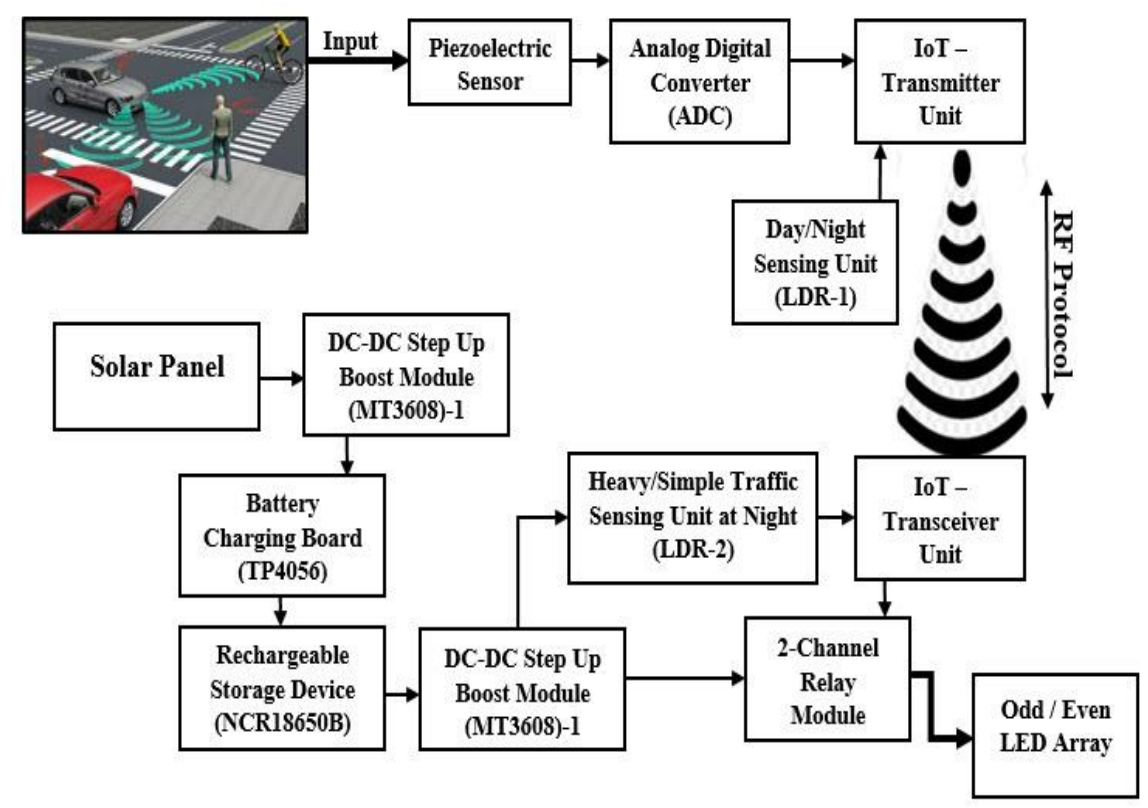

Fig. 1: Block Diagram of the Proposed Smart Street Lighting System

In Fig. 2, flow chart explicates the operation process of the proposed smart street lighting system during the lack of illumination in the evening time. It starts with a decision from LDR1 , only when there is no adequate daylight; however, the IoT transmitter controller unit sends a decision to switch ON the system and controls the street light mechanism [8]. At this moment, the street lights with a partial intensity in a Z-shaped lighting system. Once the system switched ON, the IoT transmitter controller unit will be waiting for a signal from the embedded deployed piezoelectric sensors. Hence, if any movement of vehicles or pedestrians detected by the piezoelectric sensor, it would send another wireless digital HIGH signal to the IoT transceiver controller unit. Thus, the streetlights with entire intensity in a full capacity illumination for a certain counted time (ONE-minute), then returned to a Z-shaped lighting system. 


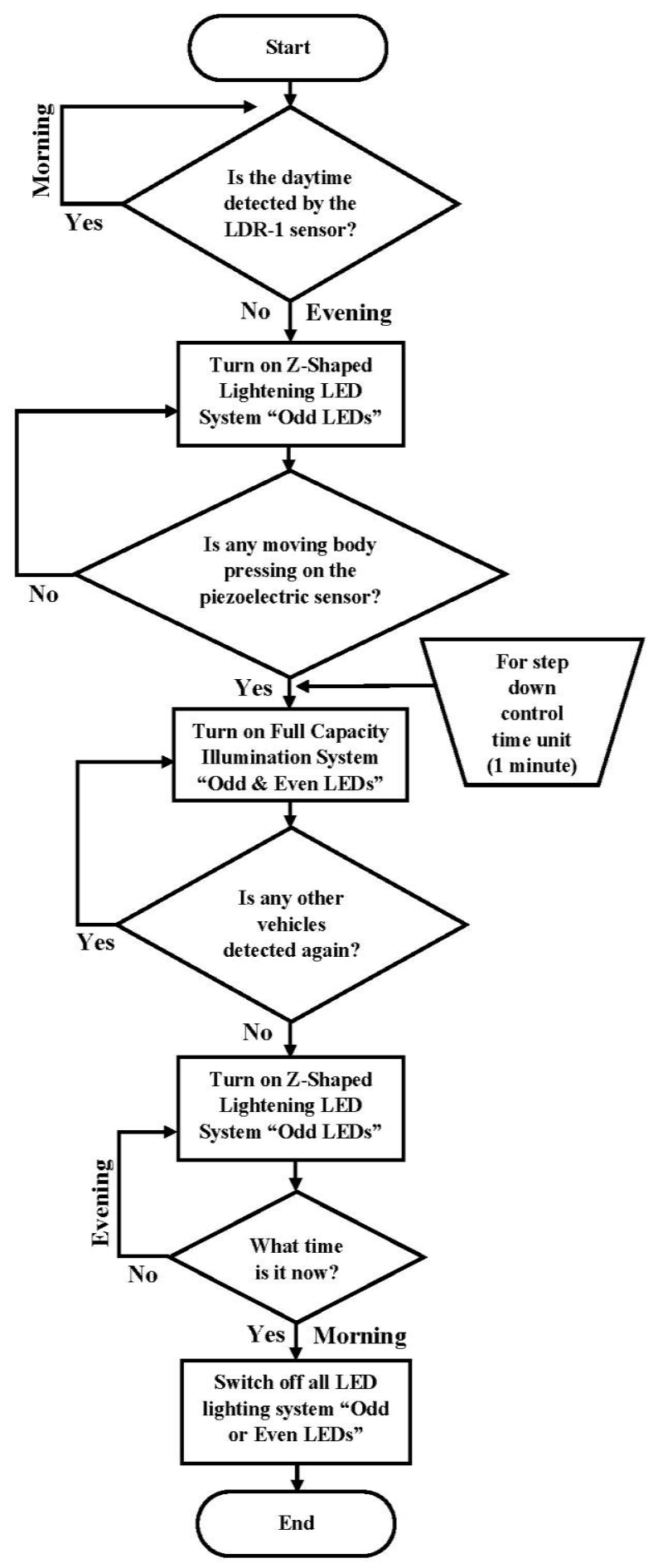

Fig. 2: Flowchart of the Proposed Smart Street Lighting System

\section{IMPLEMENTATION}

The major components utilized in our proposed project listed below in the following Fig. 3, while a brief touch of discussion for the specifications of each relevant component shown below. However, the whole construction of the working circuit for the smart street lighting system shown in the following Fig. 4. It is noticeable that all components chosen after analysing their specifications carefully $[4,5]$. 


\subsection{Major Components Used for Proposed Smart Street Lighting System}

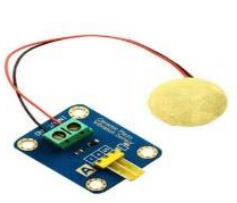

a)

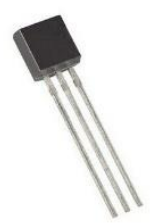

b)

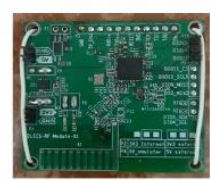

c)

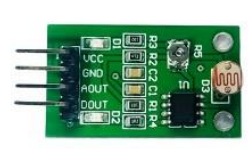

d)

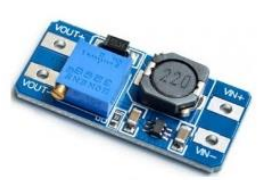

e)

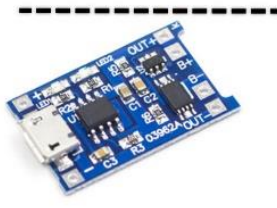

f)

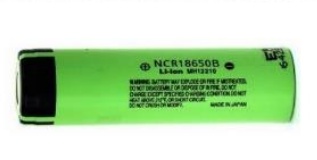

g)

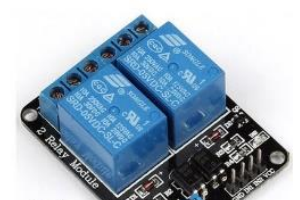

h)

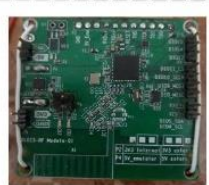

i)

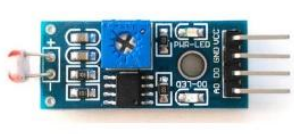

j)

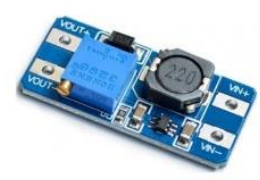

k)

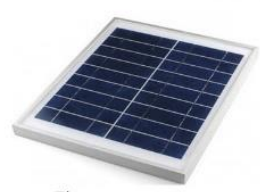

l) m)

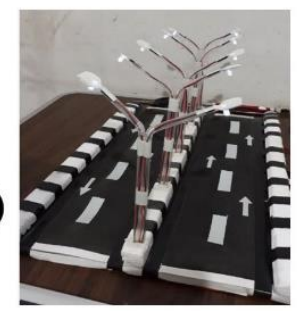

Fig. 3: Main Components Used in the Proposed Smart Street Lighting System

a) Piezoelectric Transducer: utilized as a knock sensor to detect the movement of vehicles and pedestrians on the roads. A change in mechanical energy (pressure or stress) produces an electrical signal as an output, which is the basic working principle of piezoelectric transducers. Whenever there is a vibration or pressure over the piezoelectric transducer, it produces an electrical output signal, which given to the IoT transmitter controller unit as a digital value after converting it from analog to digital signal.

b) Transistor NPN 2222: an analog-to-digital converter circuit achieved by using the transistor NPN 2222 and resistors, in order to generate an electronic approach, where variable analog signals which are continuously changed without any altering to their essential contents, and it will be modified into multiple levels of digital signals.

c) IoT Card-Transmitter Controller Unit: communicating a network of physical things that embedded within the system as the sensors, for the goal of connecting and transferring data within other systems and devices. Also, it is utilized to accept the converted signal from the ADC circuit, where the analog signal of the piezoelectric vibration disk which represents the number of vehicles that pass during any stress on it; in addition to receiving another signal from light-dependent resistor module to differentiate between the two states in the day which are morning and evening.

d) Light-Dependent Resistor Sensor Module (LDR-1): used to distinguish between the intensity of light. Hence it send out a digital signal to the IoT card - transmitter controller unit; where it let it have the possibility to know the difference between daylight and dark at any time, thus this leading the street lighting probes not to be illuminated except in the right time.

e) DC-DC Adjustable Step-Up Boost Module (MT3608- No;1): it is the most low-cost module that can step-up a range from a DC input voltage of $2.5 \mathrm{~V}$ to $24 \mathrm{~V}$ up to a DC output voltage of $5 \mathrm{~V}$ to $28 \mathrm{~V}$, including a range of max. DC electric current reaches up to $1.5 \mathrm{~A}$. Hence, $5 \mathrm{~V}$ DC output voltage 
gained from the step-up boost module will be ready connected to a battery charger module as a DC input voltage.

f) Battery Charging Board (TP4056): manufactured especially for charging electrochemical storage devices as lithium-ion rechargeable batteries; where, this module characterized by using a particular way in charging li-ion batteries, which depends on applying a distinguished manner by using a constant current and constant voltage $(\mathrm{CC} / \mathrm{CV})$. That method named as complete linear charging technique for lithium-ion batteries that including single cell.

g) Panasonic (NCR18650B) Rechargeable Battery: its proper name is 18650 cell. The voltage of the 18650 cell is $3.7 \mathrm{~V}$ while its stored charged current ranged between $1800 \mathrm{mAh}$ to $3500 \mathrm{mAh}$ (mill-ampere-hours). Where its importance abridged to be the main source of power that supporting all modules installed in the system at the evening time.

h) 2 Channel Relay Module: defined as a relay interfaced board, this powered relay module considered as an electrical switch that operated if its electromagnetic condition is utilized. Where the main aim that was acquired from the 2 channel relay module was firstly for supporting LEDs at night (First Group $=$ Z-Shape) with the required power to be lighted when there were no vehicles at this time. While the second goal was for connecting both groups of LEDs with the necessary power to light when there was a heavy traffic situation.

i) IoT Card-Transceiver Controller Unit: it is receiving a signal from the Optical Sensitive Resistance Light Detection Sensor Module to differentiate between two states on the street at night, where if there was a heavy traffic or a simple vehicles' movement. While the other task is sending the input control signal for the 2 channel relay module, so here the input control signal would have the ability to light one group of LEDs when there was a simple vehicles movement or both groups if there was a heavy traffic situation.

j) Optical Sensitive Resistance Light Detection (LDR-2): used to transmit a digital signal to the IoT card - transceiver controller unit; where it gave IoT card - transceiver controller unit the availability to distinguish at night between the status of the heavy traffic and the simple vehicles' movement. Hence when the optical sensitive resistance light detection sensor module (LDR-2) is high, it would be sending a digital output signal to the IoT card - transceiver controller unit. Thus, a permission signal sent to the 2-channel relay module to turn on either one group of LEDs (ZShaped Lightening System) if there was a simple vehicles' movement or the two groups of LEDs if there was a heavy traffic situation. On the other hand, when the optical sensitive resistance of the light detection sensor module (LDR-2) is low; it would be sending a digital output signal to the IoT card - transceiver controller unit. Thus, another permission signal sent to the 2-channel relay module to turn off both groups of LEDs due to the presence of daylight state, when there was no need to any lighting system of LEDs.

k) DC - DC Adjustable Step-Up Boost Module (MT3608-No;2): it is a multi-adjustable DCDC boost module; it used to step up a DC input voltage of $3.3 \mathrm{~V}$ to be a DC output voltage of $5 \mathrm{~V}$. At this moment, the role of the potentiometer trim pot is arising, where its adjustment needed to get the wanted output voltage value. Hence, the 5V DC output voltage obtained; this 5V DC output voltage transmitted to be as the input power source for a 2-channel relay module, so they both operated successfully.

1) Solar Panel: A Poly-Crystalline or Multi-Crystalline solar panel that consists of several crystals of silicon in a single photovoltaic (PV) cell. Where it used in our project to make an energy-harvesting system that depends on collecting a clean renewable energy source from sunlight and converting that light energy into an electrical power source. 
m) LED Lamps Array: the technique of the Z- shaped lightening system for roadway LED lamps aimed to gain the maximum range of the depleted energy from the street and save more expenses in lightening roadways. Hence, this manner applied when there was a simple vehicle's movement in the streets, where the enlightening of the LED lamps along the street will take a Z-shaped method to ensure the required level of security for all walkers or pedestrians even there was no heavy traffic. Therefore, a low-cost powered lightened roadway obtained favorably. While the full capacity illumination technique will be achieved if there was a heavy traffic situation detected in the roadway.

5.2. The Operated Constructed Circuit For Smart Street Lighting System: When the vehicles pass over the roadways especially at night, there is a stress applied by the moving vehicle on the piezo transducer [5]. This converted digital signal transmitted to IoT-transmitter unit to be processed and wirelessly send to IoT-transceiver to take a decision for lighting LEDs of group-1 only or both group-1 \& group-2 according to the traffic situation. Hence, our proposed project affords the ability to control the squandered energy in streetlights smartly.

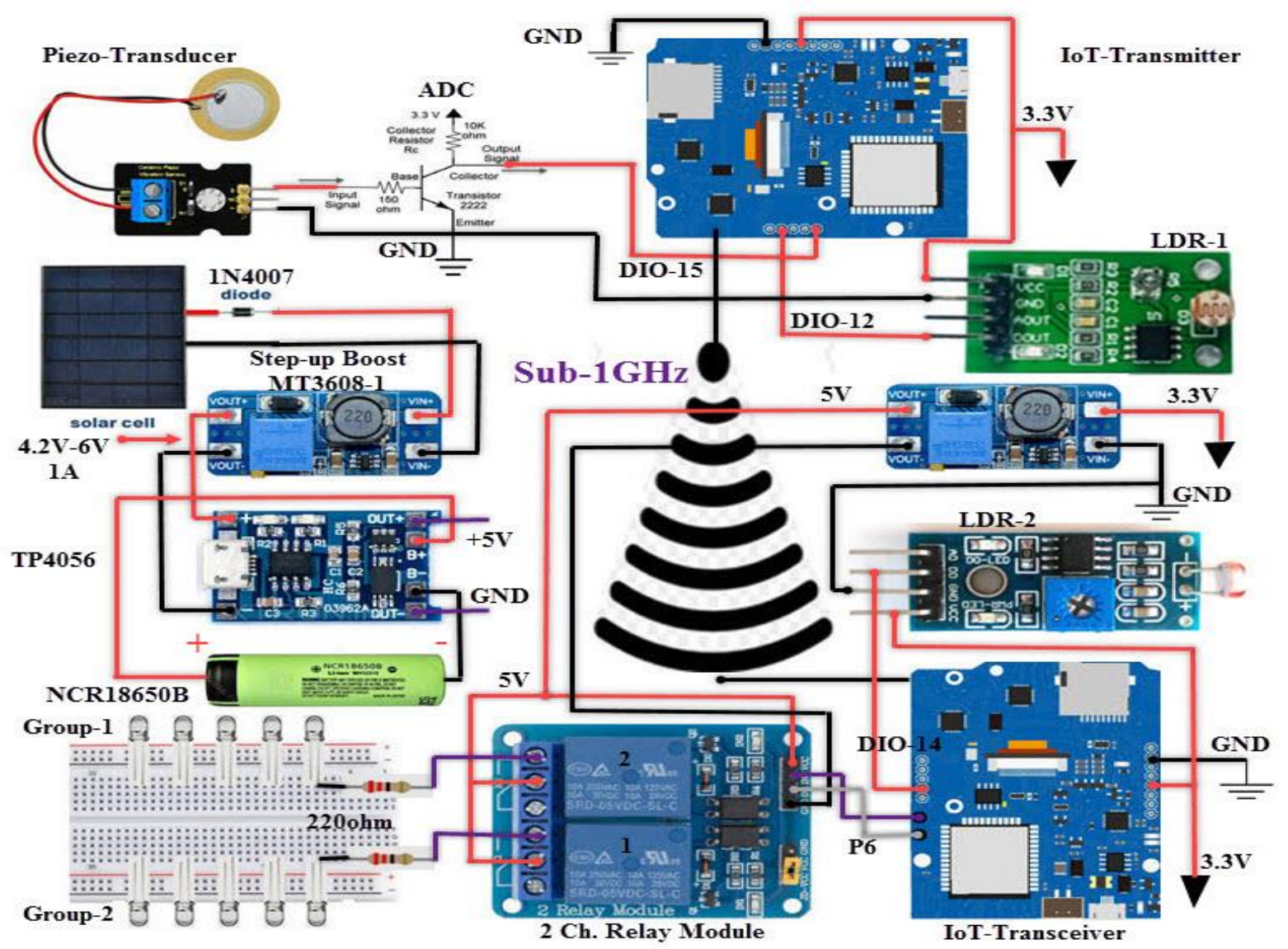

Fig. 4: Project Circuit Construction

\section{RESULTS}

The various results of the actual project experiments conducted and listed down in the following Table 1 below. For demo purposes, these values of currents, voltages, and power consumption recorded below. However, for the actual implementation of this project, the values of electrical voltage and current generated will be much higher because of tremendous stress applied by the vehicles, where, for the practical purposes, the piezo disc will be replaced by a PZT layers of sheets, which have a much more robust piezoelectric influence $[4,10]$. 


\begin{tabular}{|c|c|c|}
\hline No; & Parameters & Calculated results \\
\hline 1 & $\begin{array}{l}\text { Proposed project } \\
\text { average power }\end{array}$ & $\begin{array}{l}\text { - LED Forward Current }\left(\mathbf{I}_{\mathbf{F}}\right)=5 \mathrm{~mA} \\
\text { - LED Forward Operating Voltage }\left(\mathbf{V}_{\mathbf{F}}\right)=2.7 \mathrm{~V} \\
\text { - } \text { LED Power Dissipation }\left(\mathbf{P}_{\mathbf{d}}\right)=\left(\mathbf{I}_{\mathbf{F}}\right) \mathrm{X}\left(\mathbf{V}_{\mathbf{F}}\right)=13.5 \mathrm{~mW} 15 \mathrm{~mW} \\
\text { - } \text { Group-1 Power Dissipated }\left(\mathbf{P}_{\text {Group1 }}\right) \text { of }(5 \mathrm{LEDs})= \\
\left(\mathbf{P}_{\mathbf{d}}\right) \mathrm{X}(5 \mathrm{LEDs})=15 \mathrm{mWX}=75 \mathrm{~mW} \\
\text { - } \text { Group-Shaped Lighting System }] \\
\text { - Total Average Power Dissipated }\left(\mathbf{P}_{\text {T-avg }}\right)=\left(\mathbf{P}_{\text {Group1 }}\right)+ \\
\left(\mathbf{P}_{\text {Group2 }}\right)=75 \mathrm{~mW}+75 \mathrm{~mW}=150 \mathrm{~mW} \\
{[\text { Full Capacity Illumination }]}\end{array}$ \\
\hline 2 & $\begin{array}{c}\text { Li-ion } \\
\text { rechargeable } \\
\text { battery } \\
\text { supporting } \\
\text { working life for } \\
\text { the whole } \\
\text { system }\end{array}$ & 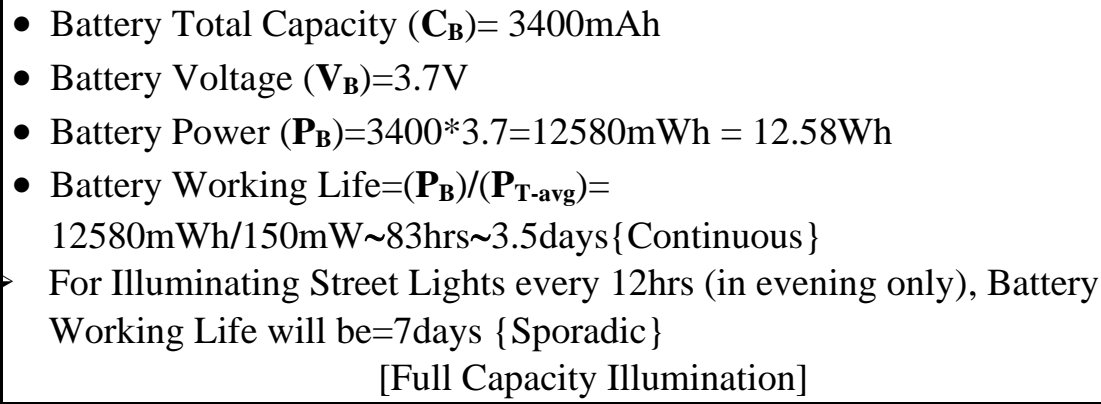 \\
\hline
\end{tabular}

Table 1: Proposed Project Calculations

\section{CONCLUSIONS}

Obviously, the design and the development of various sensors are responsible to automate the multiple processes in our life, where the desire to use self-powered devices drives us to achieve enormous growth in the field of energy harvesting; where electricity demand is increased, so a new mechanism is required to produce electrical power. For that, this research paper proposed an electricity-efficient approach to automate the streetlights in roadways [7]. In addition, wireless sensor networks (WSN) present a new solution to bring the installed cost down due to eliminating wired connections and to ensure energy efficiency. However, the integration of a solar panel with a charge controller module having a rechargeable battery management system which considered a clean power-saving factor, that supports the whole system with the need for electric power. Finally, streetlights are the essential backbone of smart cities in illumination [5], where LEDs are a vital lighting option due to their peculiar low power consumption and cost-effective nature. Hence, the proposed prototype will help in eliminating the current sodium vapour lamps or white metal halide lamps, where LED comprised, lamps will operated smartly by the managed control from IoT controller units, light-dependent resistor (LDR), and piezoelectric transducer [6].

\section{REFERENCES}

[1] Shashank Priya and Daniel J. Inman. (2009). Energy Harvesting Technologies. $1^{\text {st }}$ edi., pp. 09-16. Springer Science+Business Media, LLC. New York, USA.

[2] Mickaël Lallart. (2012). SMALL SCALE ENERGY HARVESTING. $1^{\text {st }}$ edi., pp. 145-167. InTech Prepress. Rijeka, Croatia.

[3] Alper Erturk and Daniel J. Inman. (2011). PIEZOELECTRIC ENERGY HARVESTING. 1st edi., pp. 01-14. WILEY Publication. West Sussex, UK. 
[4] Bait, M. M.; Borase, R. S; and Dange, K. (2019). IoT Based Energy Efficient System for Streets. pp. 01-05. International Journal of Engineering Science and Computing. Vol. 09, Issue No; 05. Bangalore, India.

[5] S. Ahmad; A. Siddique; K. Iqbal; A. Hussain; and A. Ijaz. (2021). IoT Based Smart Street Lights Empowered By Piezoelectric Sensors. pp. 341-345. International Journal of Scientific \& Technology Research. Vol. 10, Issue No; 01.

[6] S. P. Beeby, M. J. Tudor, and N. M. White. (2006). Energy harvesting vibration sources for microsystems applications. pp. R175-R195. Measurement Science and Technology Journal. Vol. 17, Number: 12. IOP Publishing. Bristol, UK.

[7] Denis O. Urroz-Montoya, Jeffrey R. Alverto-Suazo, Julio R. García-Cabrera, and Cesar H Ortega-Jiménez. (2019). Piezoelectricity: a literature review for power generation support. pp. 01-06. MATEC Web of Conferences (ACMME 2019). Vol. 293, Article Number: 05004.

[8] R. Abinaya, V. Varsha, and Kaluvan Hariharan. (2016). An Intelligent Street Light System based on Piezoelectric Sensor Networks. pp. 01-06. Indian Journal of Science and Technology. Vol. 09, Issue No; 43.

[9] Keyur K. Patel, Sunil M. Patel, and PG Scholar. (2016). Internet of Things-IOT: Definition, Characteristics, Architecture, Enabling Technologies, Application \& Future Challenges. pp. 6122-6131. International Journal of Engineering Science and Computing. Vol. 06, Issue No; 05.

[10] Prameela Kumari N., Abhi Bharadwaj K., Amaranath D. K. M., Santhosh B. P., and Syed Mazhar Mohiuddin. (2020). Smart Street Light System Using Piezoelectric Transducer and IR Sensor. pp. 3732-3738. International Journal of Advance Science and Technology. Vol. 29, No. 10S.

[11] A. Arnau. (2004). Piezoelectric Transducers and Applications. 1st edi., pp. 01-20. SpringerVerlag Berlin Heidelberg. New York, USA. 